American Journal of Applied Sciences 6 (4): 631-637, 2009

ISSN 1546-9239

(C) 2009 Science Publications

\title{
Reliability-Based Earthquake Design of Jacket-Type Offshore Platforms Considering Pile-Soil-Structure Interaction
}

\author{
Behrouz Asgarian and Hossein Agheshlui \\ Faculty of Civil Engineering K.N.Toosi University of Technology, \\ 19967-15433, Tehran, Iran
}

\begin{abstract}
There are plenty of uncertainties in environmental condition of ocean and also in platform element capacities. Reliability-based method could consider these uncertainties. A reliability-based earthquake design method was used to determine the earthquake LRFD parameters for two conventional, steel, pile-supported (template-type) offshore platforms located in the Persian Gulf. The pile-soil-structure interaction, the buckling and postbuckling behavior of the braces were considered. Two steel platforms were simulated accurately by the finite element program Opensees. Field data were assumed based on past studies. Sensitiveness of reliability-based method was studied. It was found that the geometry of jacket and different types of braces was important in the capacity and the behavior of offshore platforms. Finally the calculated LRFD elements resistance factors for these two platforms were compared with API recommended factors and it was observed that API recommended element resistance factors were more appropriate for SSL 3.
\end{abstract}

Keywords: Reliability, jacket, foundations, pushover analysis, buckling

\section{INTRODUCTION}

More than 100 pile-supported (template-type) steel platforms have been constructed in the high-activity seismic regions all over the world and some others are in design and construction levels. The seismic design of these structures should be performed accurately and the failure risk should be decreased as much as possible considering the economical aspects.

$\mathrm{Bea}^{[1]}$ in a cooperation with API and ISO studied the seismic design procedure in various high-activity seismic regions such as offshore California, Alaska, New Zealand, Japan, Indonesia, Venezuela and the Caspian Sea and then he presented a step-by-step method for reliability-based earthquake design of offshore platforms. Using this method, the reliabilitybased earthquake design could be performed in any region with any specific geotechnical and seismic properties.

Asgarian, Aghakouchak and $\mathrm{Bea}^{[2]}$ formulated a nonlinear fiber element for analysis of jacket type offshore structures. The element predicted buckling load and post buckling behavior of strut members accurately. It also produced fairly accurate results for yield load and post yield behavior of portal members.
This element was verified using the experimental data for individual strut and portal members subjected to cyclic displacements. The results were in good agreement with experiments and the results of other analytical models.

The response of offshore platforms is completely dependent on the foundation. It is clear that exact modeling of the foundation and considering the soilpile-structure interaction is necessary to evaluate the results accurately. The methods of analyzing the seismic soil-pile-structure interaction consist of 2D and $3 \mathrm{D}$ modeling of the pile and soil continuum using finite element or finite difference methods, dynamic beam on a nonlinear Winkler foundation (i.e., dynamic p-y) methods and simplified two-step methods that uncouple the superstructure and foundation portions in the analysis. In this research, the beam on nonlinear Winkler foundation (BNWF) method is used to model the pile-soil-structure interaction coupled with the response of superstructure.

Boulanger et al. ${ }^{[3]}$ used a modified BNWF model with a series of radial dampers and $\mathrm{p}-\mathrm{y}$ curves to define the soil stiffness. The results of this research were verified with the results of a laboratory test which had been done by Wilson et al. on a single steel pile at

Corresponding Author: Hossein Agheshlui, Faculty of Civil Engineering K.N.Toosi University of Technology,

No: 1346 Vali Asr Street, Mirdamad Crossing, P.O.Box: 15875-4416, Postcode: 19967-15433,

Tehran-Iran Tel: +98-21-88779623, Fax: +98-21-88779623 
Davis University in California. Although this model has been used to analyze dynamic loadings, it could also be used for static loadings which were considered in this research.

Bentley and El-Naggar ${ }^{[4]}$ studied the dynamic lateral behavior of piles considering pile-soil interaction using a BNWF model. There was a good agreement between the results of their study and the results of analytical models.

\section{MATERIALS AND METHODS}

The procedure used in this study for Reliabilitybased earthquake design is based on the API LRFD formulation for design of the elements that comprise offshore platforms (Recommended 1993) ${ }^{[5]}$ :

$$
\phi_{\mathrm{E}} \mathrm{R}_{\mathrm{E}} \geq \gamma_{\mathrm{D} 1} \mathrm{D}_{1}+\gamma_{\mathrm{D} 2} \mathrm{D}_{2}+\gamma_{\mathrm{L} 1} \mathrm{~L}_{1}+\gamma_{\mathrm{E}} \mathrm{E}
$$

where, $\phi_{\mathrm{E}}$ is resistance factor for earthquake loadings, $\mathrm{R}_{\mathrm{E}}=$ design capacity of the platform elements (e.g., brace, joint, pile) for earthquake loadings as defined by the API RP 2A-LRFD guidelines, $\gamma_{\mathrm{D} 1}=$ self-weight of the structure (dead) loading factor, $\mathrm{D}_{1}=$ design dead load, $\gamma_{\mathrm{D} 2}=$ imposed equipment and other objects loading factor, $\mathrm{D}_{2}=$ design equipment loading, $\gamma_{\mathrm{L} 1}=$ consumables, supplies and vessel fluids (live) loading factor, $\mathrm{L}_{1}=$ live loading, $\gamma_{\mathrm{E}}=$ earthquake loading factor, and $\mathrm{E}=$ earthquake loading effect developed in the structure or foundation element.

The reliability-based earthquake design method presented by $\mathrm{Bea}^{[1]}$ is a step-by-step procedure that considers the following steps.

Step 1: Defining the Structural Safety Level (SSL).

Step 2: Determining the Earthquake Hazard Zone (EHZ) for the platform, based on the geographical location.

Step 3: Determining if the local seismic studies are necessary or not.

Step 4: Defining the shape of the normalized mean (average) elastic principal horizontal acceleration response spectra component.

Step 5: Evaluating the uncertainties associated with the elastic response spectra ordinates and the methods used to determine the forces induced in the platform elements by earthquakes.

Step 6: Determining the earthquake loading factor.

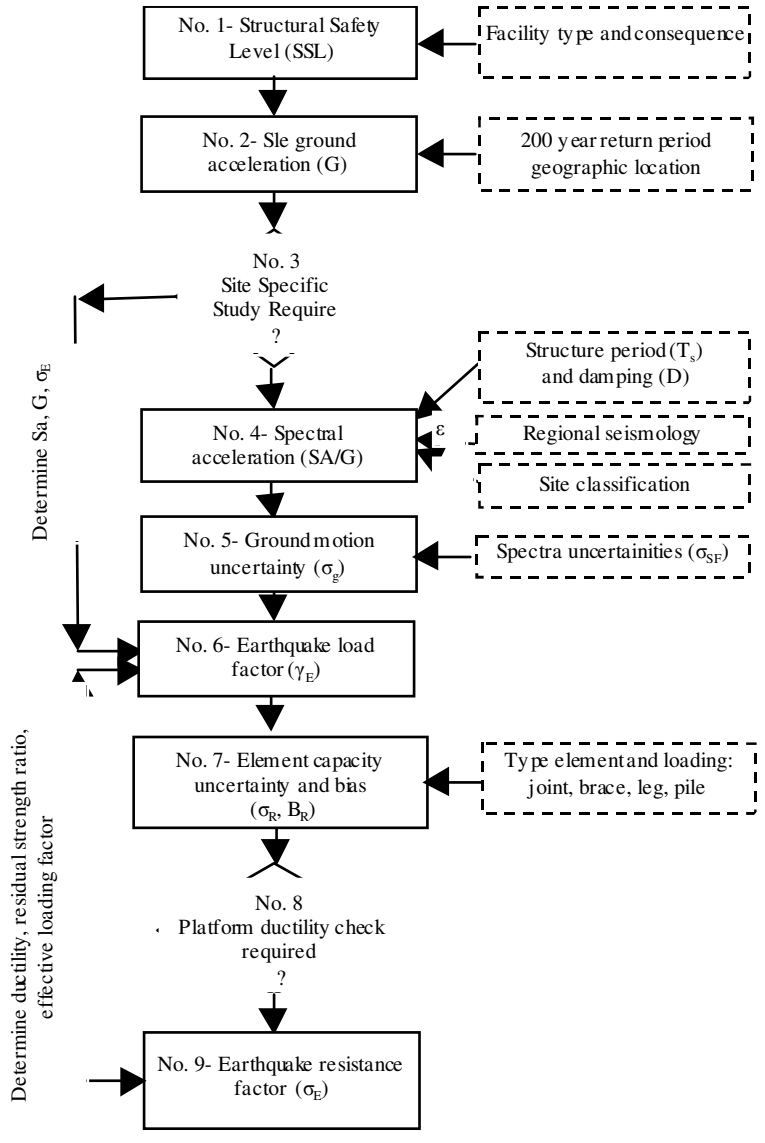

Fig. 1: Reliability-based LRFD procedure ${ }^{[1]}$

Step 7: Evaluating the biases and uncertainties involved in the evaluation of the platform element static loading (design) capacities.

Step 8: Determining RSR factor.

Step 9: Determine the platform element resistance factor.

The reliability-based earthquake LRFD procedure was outlined in Fig. 1.

To evaluate the parameters of reliability-based earthquake design, structural models of two newly designed platforms located in Persian Gulf have been made using the finite element program OPENSEES (Open System for Earthquake Engineering Simulation) and displacement control static pushover analysis was performed. General sketch of these models were shown in Fig. 2 and 3. In addition, in the modeling of platforms, general geometry and main elements that significantly affect the platform behavior were modeled. 


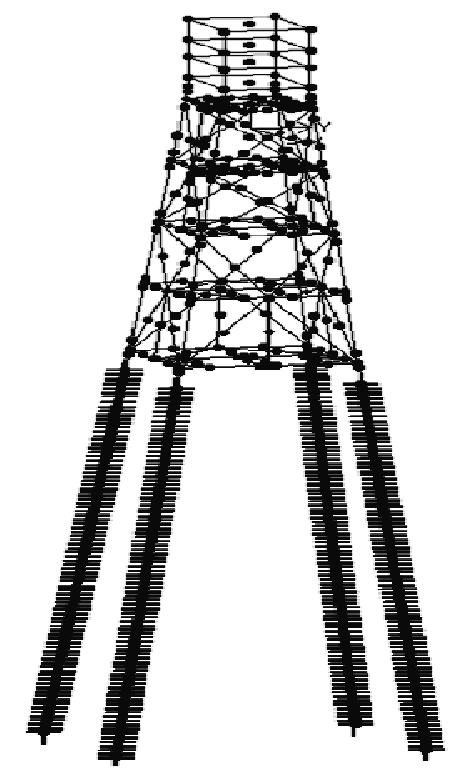

Fig. 2: General sketch of the platform SP1

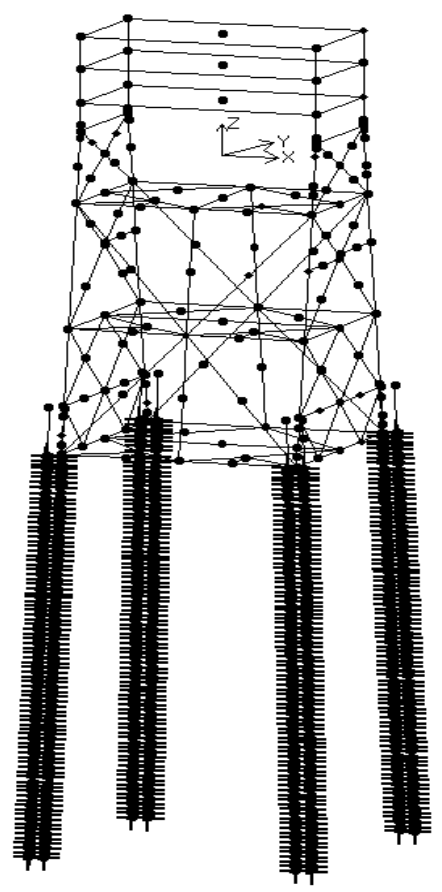

Fig. 3: General sketch of the Platform SP2

The weight of the deck was applied as concentrated loads on four nodes located at the corners of the deck at different elevations. By considering the added mass, marine growth and entrapped fluid, The weight of jacket was applied as concentrated loads on the corner joints at different elevations of jacket.

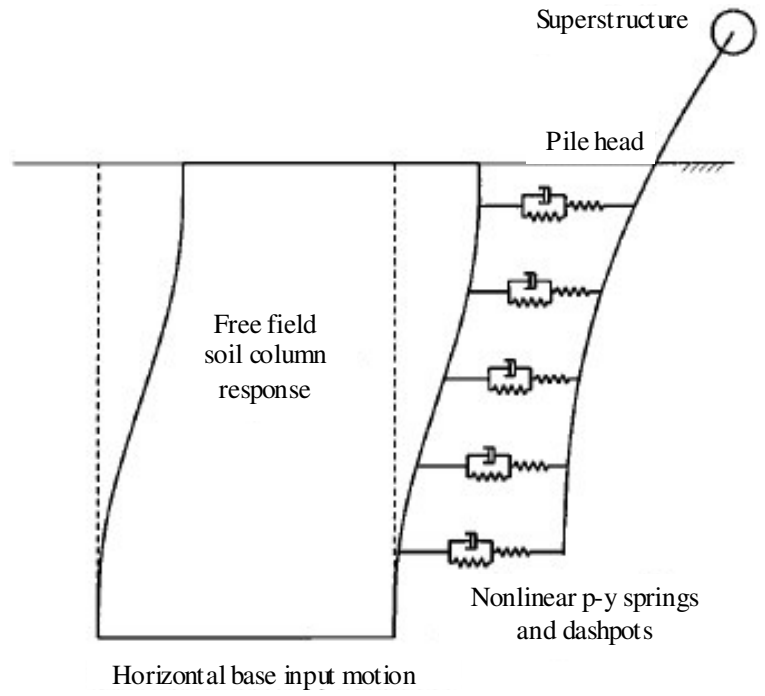

Fig. 4: Schematic view of the dynamic p-y analysis model $^{[3]}$

Structural analysis was carried out using nonlinear finite element method and the elements were modeled using fiber sections. Moreover, the jacket and the deck elements were modeled using nonlinear beam-column elements which were based on the iterative force formulation while they have the ability to consider the spread of plasticity along the element ${ }^{[6]}$.

In order to evaluate the realistic behavior and the lateral capacity of the jacket, it was necessary to consider the buckling of braces. For this purpose, an initial imperfection of $1 / 1000$ of the length of the brace was applied at the midspan of the braces ${ }^{[2]}$. To consider geometrical stiffness, corrotational formulation was also used.

Soil-pile-structure interaction was considered using Beam on Nonlinear Winkler Foundation model (BNWF). Lateral and vertical soil stiffness and end bearing were considered using $\mathrm{p}-\mathrm{y}, \mathrm{t}-\mathrm{z}$ and $\mathrm{q}-\mathrm{z}$ nonlinear models respectively. P-y method was shown in Fig. $4^{[3]}$.

The nonlinear $\mathrm{p}-\mathrm{y}$ behavior is conceptualized as consisting of elastic $\left(\mathrm{p}-\mathrm{y}^{\mathrm{e}}\right)$, plastic $\left(\mathrm{p}-\mathrm{y}^{\mathrm{p}}\right)$ and gap $\left(\mathrm{p}-\mathrm{y}^{\mathrm{g}}\right)$ components in series. Radiation damping is modeled by a dashpot parallel to the elastic ( $\left.\mathrm{p}-\mathrm{y}^{\mathrm{e}}\right)$ component. The gap component consists of a nonlinear closure spring $\left(\mathrm{p}^{\mathrm{c}}-\mathrm{y}^{\mathrm{g}}\right)$, parallel to a nonlinear drag spring $\left(\mathrm{p}^{\mathrm{d}}-\mathrm{y}^{\mathrm{g}}\right)$, as shown in Fig. $5^{[3]}$. The characteristics of the p-y spring components were illustrated in Fig. $5^{[3]}$. Since static analysis was used here, damping was not considered.

Shape of the $p-y, t-z$ and $q-z$ curves suggested by API was used in the modeling and in the analysis. It was assumed that the piles were plugged. 


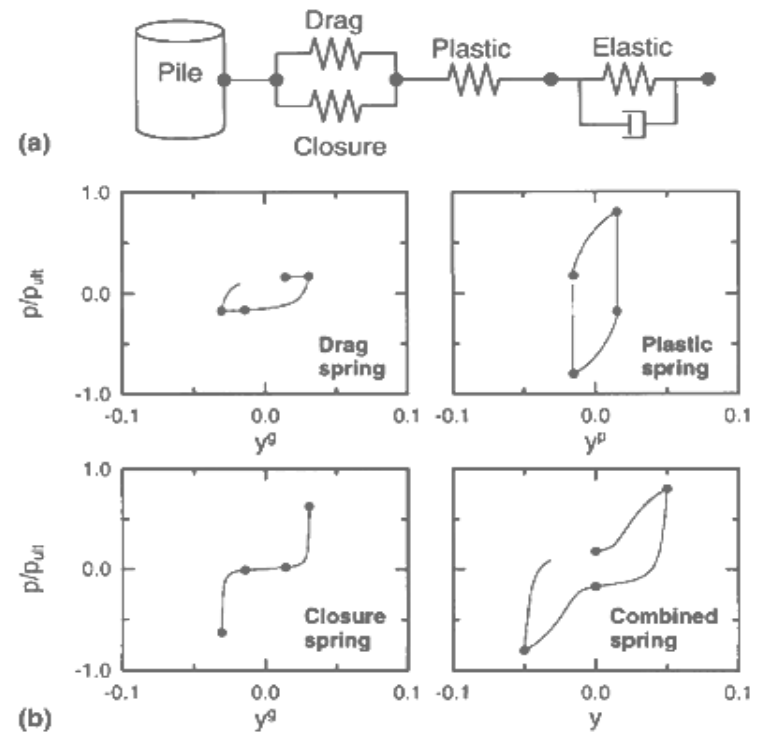

Fig. 5: Characteristics of nonlinear p-y element: (a) Components, (b) Behavior of the components ${ }^{[3]}$

The peak response of the elastic structure due to its $\mathrm{n}^{\text {th }}$ vibration mode can be exactly determined by pushover analysis of the structure subjected to lateral forces distributed over the height of the structure, according to $\mathrm{s}_{\mathrm{n}}=\mathrm{m} \Phi_{\mathrm{n}}$, where $\mathrm{m}$ is the mass matrix and $\Phi_{\mathrm{n}}$ its nth mode ${ }^{[7]}$.

Lateral load pattern that were used for static pushover analysis here, was according to the first and the second mode of vibration for analysis in longitudinal and transversal direction. The reason for choosing these two modes of vibration was that these were the prevailing modes of vibration in the two directions.

Both of the platforms modeled herein were manned self-contained production structures so SSL was equal to 3. However, for this SSL safety index $\beta$ is equal to 3.7 , annual probability of failure is $\mathrm{P}_{f \text { annual }}=10^{-4}$ and an annualized lifetime (20 years) probability of failure is $\mathrm{P}_{\text {fannualized }}=10^{-4} \sim 2 \times 10^{-5[1]}$.

Based on the geographical location of platforms, Persian Gulf, mean annual maximum strength level earthquake (SLE) effective ground (rock) accelerations, $\mathrm{G}$, that have the average return periods of $\mathrm{T}_{S L D}=200$ years is between $5 \mathrm{~g}$ and $15 \% \mathrm{~g}^{[1]}$.

The median earthquake effective loading factor, $\mathrm{Fe}_{50}$, is assumed to be the reciprocal of the product of these two quantities ${ }^{[8-10]}$ :

$$
\mathrm{F}_{\mathrm{e} 50}=[\mu \alpha]^{-1}
$$

There are three main sources of uncertainties in determining the earthquake-induced forces. The first source is the inherent variability due to the seismic sources and source-to-site attenuation characteristics, $\sigma_{\mathrm{SE}}$. Considering that there are deep subduction zones in Persian Gulf, $\sigma_{\text {SE }}$ will be equal to $1.4^{[1]}$. The next source of uncertainty, $\sigma_{\mathrm{GS}}$ is the local geology and soil condition which affect the ordinates of the response spectra. The soil profile under the platform consists of sand, silt and very stiff clay. Therefore $\sigma_{\mathrm{GS}}$ is equal to $0.4^{[1]}$. The third source of uncertainty is the response spectrum method used to determine the forces in the members of the platform. This uncertainty includes the modeling uncertainties contributed by evaluation of the platform mode shapes, periods and masses (including hydrodynamic effects, $\sigma \approx 0.15$ ), the combination of modes $(\sigma \approx 0.15)$, and damping (structural, hydrodynamic, foundation, $\sigma \approx 0.15$ ) and the uncertainties associated with the ductility reductions in the elastic response spectra ordinates $(\sigma \approx 0.15)$. An uncertainty of $\sigma_{\mathrm{RS}}=0.30$ is used as the base case value $^{[1,8]}$.

The three sources of uncertainty were combined to develop the resultant uncertainty in the earthquakeinduced forces, $\sigma_{E}$, as following:

$$
\sigma_{\mathrm{E}}^{2}=\sigma_{\mathrm{SE}}^{2}+{\sigma_{\mathrm{GS}}}^{2}+\sigma_{\mathrm{RS}}^{2} \Rightarrow \sigma_{\mathrm{E}}=1.49
$$

Using the results developed in the preceding steps, the earthquake loading factor, $\gamma_{E}$, was determined based on the following relationship ${ }^{[1]}$.

$$
\gamma_{\mathrm{E}}=\mathrm{Fe}_{50} \exp \left(0.8 \beta_{\mathrm{E}} \sigma_{\mathrm{E}}-2.57 \sigma_{\mathrm{E}}\right)
$$

Reserve Strength Ratio (RSR) was calculated based on Eq. $4^{[1]}$.

$$
\mathrm{RSR}=\mathrm{Fe}_{50} \exp \left(\beta \sigma-2.57 \sigma_{\mathrm{E}}\right)
$$

Where $\sigma=$ resultant uncertainty in the seismic loading effects.

$$
\sigma^{2}=\sigma_{\mathrm{E}}^{2}+\sigma_{\mathrm{PC}}^{2}
$$

$\sigma_{\mathrm{PC}}$ is uncertainty in the platform capacity and assumed to be $\sigma_{\mathrm{PC}}=0.30$.

The platform element resistance factors $\phi_{\mathrm{E}}$ were also evaluated through the following expression ${ }^{[1]}$.

$$
\phi_{\mathrm{E}}=\mathrm{B}_{50 \mathrm{RE}} \exp \left(-0.8 \beta_{\mathrm{E}} \sigma_{\mathrm{RE}}\right)
$$

Where $\mathrm{B}_{50 \mathrm{RE}}$ and $\sigma_{\mathrm{RE}}$ have been presented by $\mathrm{Bea}^{[1]}$. 


\section{RESULTS AND DISCUSSION}

Static pushover analysis of the SP1 and the SP2 specimens in $\mathrm{X}$ and $\mathrm{Y}$ directions, as outlined in Fig. 2 and 3, were shown in Fig. 6, 7, 8 and 9.

According to these diagrams, system ductility, $\mu$, (ratio of the maximum lateral displacement) and residual strength ratio, $\alpha$, (the platform residual strength ratio) of the platform SP1 were calculated as followings:

X direction: $\mu=2.29, \alpha=0.984$

Y direction: $\mu=3.04, \alpha=0.947$

Based on Eq. 2, for platform SP1:

$\mathrm{X}$ direction: $\mathrm{F}_{\mathrm{e} 50}=0.444$

Y direction: $\mathrm{F}_{\mathrm{e} 50}=0.348$

For the platform SP2, above parameters were as followings:

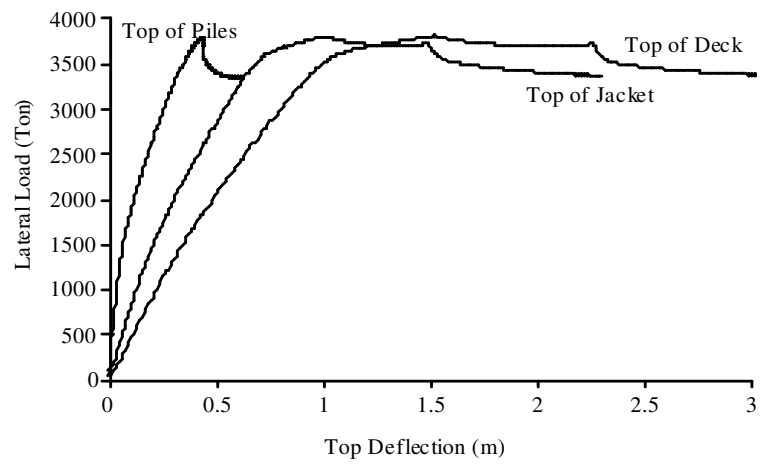

Fig. 6: Static pushover analysis of platform SP1_X direction

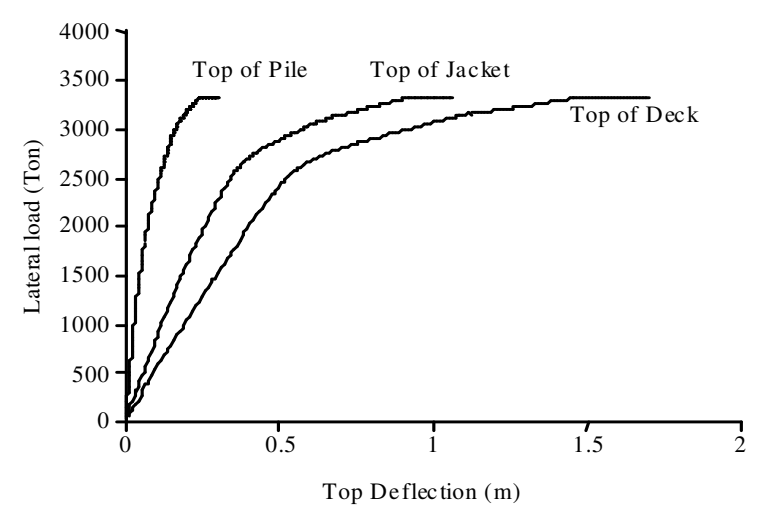

Fig. 7: Static pushover analysis of platform SP1_Y direction
$X$ direction: $\mu=2.04, \alpha=0.989, F_{\mathrm{e} 50}=0.496$

Y direction: $\mu=3.91, \alpha=0.986, \mathrm{~F}_{\mathrm{e} 50}=0.259$

As a result of Eq. 3, earthquake loading factors for SP1 in X and Y directions were 0.794 and 0.622 respectively. Similarly for SP2 these factors were 0.887 and 0.672 .

Using Eq. 4, RSRs for two platforms were tabulated in Table 1.

In the Table 2, the resistance factors evaluated based on the reliability based method, were compared with the API RP 2A-LRFD recommended factors.

The effect of changes in some important parameters on the results of the reliability-based method was studied.

Two different structural safety levels were assumed. Variations caused due to mentioned levels in elements resistance factors, earthquake loading factor and system ductility were discussed in Table 2, 3 and 4 respectively.

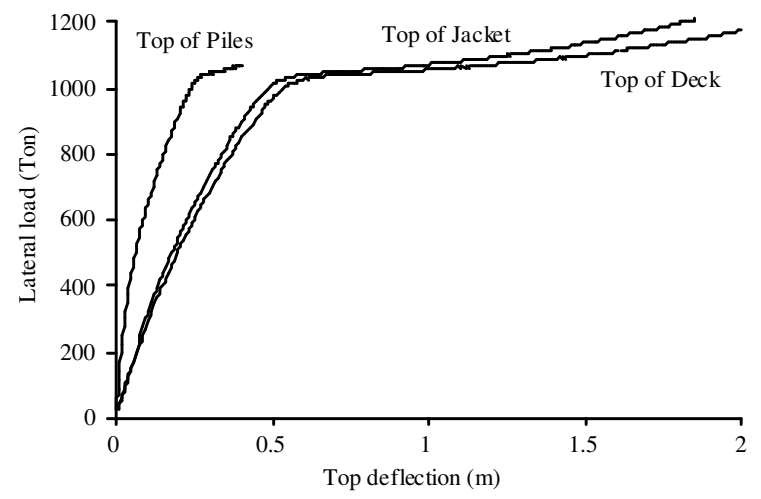

Fig. 8: Static pushover analysis of platform $\mathrm{SP}_{2} \mathrm{X}$ direction

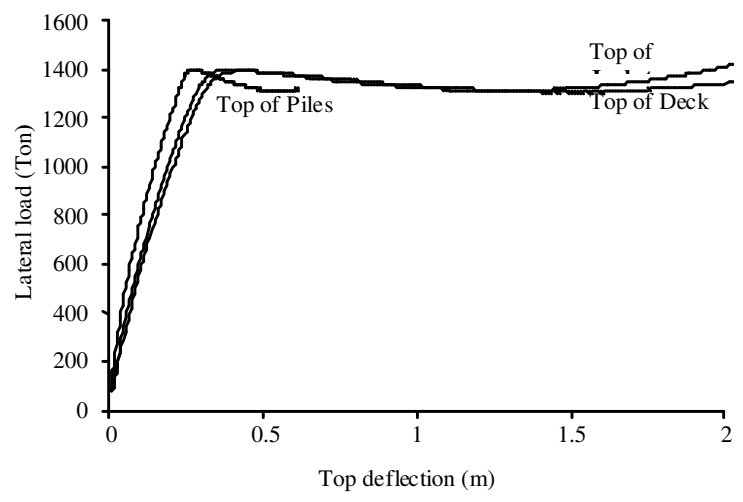

Fig. 9: Static pushover analysis of platform SP2_Y direction 
Am. J. Applied Sci., 6 (4): 631-637, 2009

Table. 1: RSRs for the two platforms

\begin{tabular}{lll}
\hline & X Direction & Y Direction \\
\hline SP1 platform & 2.67 & 2.09 \\
SP2 platform & 2.98 & 1.56 \\
\hline
\end{tabular}

Table. 2: Comparison of elements resistance factors for SSL2, SSL3 and API recommended factors

\begin{tabular}{|c|c|c|c|}
\hline \multirow[b]{2}{*}{ Elements (1) } & \multicolumn{2}{|l|}{$\Phi_{\mathrm{E}}(2)$} & \multirow{2}{*}{$\begin{array}{l}\text { API } \\
\text { recommended } \\
\Phi_{\mathrm{E}}(3)\end{array}$} \\
\hline & SSL 2 & SSL 3 & \\
\hline \multicolumn{4}{|l|}{ (a) Structures } \\
\hline \multicolumn{4}{|l|}{ Joints T, Y, DT } \\
\hline Compression & 1.03 & 0.96 & 0.96 \\
\hline Tension & 0.74 & 0.61 & 0.90 \\
\hline \multicolumn{4}{|l|}{$\mathrm{K}$} \\
\hline Axial & 0.97 & 0.89 & 0.95 \\
\hline In-plane bending & 1.24 & 1.15 & 0.95 \\
\hline Out-plane bending & 1.10 & 1.03 & 0.95 \\
\hline \multicolumn{4}{|l|}{ Braces } \\
\hline Tension & 1.01 & 0.97 & 0.95 \\
\hline Compression & 0.97 & 0.90 & 0.85 \\
\hline Bending & 1.17 & 1.12 & 0.95 \\
\hline Hydrostatic & 1.09 & 1.04 & 0.80 \\
\hline \multicolumn{4}{|l|}{ (b) Foundation } \\
\hline \multicolumn{4}{|l|}{ Piles } \\
\hline \multicolumn{4}{|l|}{ Axial Loads } \\
\hline Clays & 0.93 & 0.77 & 0.80 \\
\hline Sands & 0.29 & 0.23 & 0.80 \\
\hline \multicolumn{4}{|l|}{ Lateral loads } \\
\hline Clays & 0.71 & 0.62 & 0.80 \\
\hline Sand & 0.41 & 0.34 & 0.80 \\
\hline
\end{tabular}

Table. 3: Comparison of earthquake loading factor and the system ductility of SP1 for SSL2 and SSL3

\begin{tabular}{lll}
\hline & SSL 2 $(\beta=3.1)$ & SSL 3 $(\beta=3.7)$ \\
\hline$\gamma_{\mathrm{E}}$ & 0.388 & 0.794 \\
RSR & 1.073 & 2.672 \\
\hline
\end{tabular}

Table. 4. Comparison of earthquake loading factor and system ductility of SP2 for SSL2 and SSL3

\begin{tabular}{lll}
\hline & SSL 2 $(\beta=3.1)$ & SSL 3 $(\beta=3.7)$ \\
\hline$\gamma_{\mathrm{E}}$ & 0.388 & 0.794 \\
RSR & 1.073 & 2.672 \\
\hline
\end{tabular}

To consider the effect of uncertainty value, the amount of uncertainties in determining the earthquakeinduced forces was increased and decreased $25 \%$. Then, the value of earthquake loading factor and reserve strength ratio (RSR) were compared in Tables 5 and 6.

For conventional template-type, drilling and production platforms, based on the results from current evaluations of the ductility characteristics of welldesigned platforms in which the platform element capacities were defined according to API RP 2A-LRFD guidelines ${ }^{[8,9,11,12,14]}$, the mean ductility is presumed in this development as $\mu \geq 2.5$ and the mean residual strength ratio as $\alpha \geq 0.8$. Based on the study carried out by $\mathrm{Bea}^{[1]}$, RSR for platforms with $\beta=3.7$ and $\sigma_{\mathrm{E}}=1.5$ should be greater than 3 . Both of the platforms
Table. 5: Comparison of earthquake loading factor and RSR ratio of SP1 for different values of uncertainties in determining earthquake induced forces

\begin{tabular}{llll}
\hline & $\sigma_{\mathrm{E}}=1.12$ & $\sigma_{\mathrm{E}}=1.49$ & $\sigma_{\mathrm{E}}=1.86$ \\
\hline$\gamma_{\mathrm{E}}$ & 0.687 & 0.794 & 0.917 \\
RSR & 1.822 & 2.671 & 3.970 \\
\hline
\end{tabular}

Table. 6: Comparison of earthquake loading factor and RSR ratio of SP2 for different values of uncertainties in determining earthquake induced forces

\begin{tabular}{llll}
\hline & $\sigma_{\mathrm{E}}=1.12$ & $\sigma_{\mathrm{E}}=1.49$ & $\sigma_{\mathrm{E}}=1.86$ \\
\hline$\gamma_{\mathrm{E}}$ & 0.687 & 0.794 & 0.917 \\
RSR & 1.822 & 2.671 & 3.970 \\
\hline
\end{tabular}

mentioned above have the mean residual strength ratio and mean ductility in $\mathrm{Y}$ direction in that range, nonetheless, the mean ductility in $\mathrm{X}$ direction was out of this range. Both of the platforms have RSRs less than this value. The differences between the shapes of the braces in two directions and the absence of braces in the top story of platform SP2 (because of float over installation) were the reasons of this problem. In the $\mathrm{X}$ direction, only chevron braces were used, but in $\mathrm{Y}$ direction, $\mathrm{X}$ braces were also used.

Based on the results of this study and comparison presented in Table 2, following results can be concluded:

- In $\mathrm{K}$ joints exposed to in-plane and out-of-plane bending, API factors were conservative but for axially loaded $\mathrm{K}$ joints and T, Y, DT joints which were under tension, the calculated factors were conservative

- There was a good agreement between the API and this method for braces exposed to tension forces, but in other cases, the API recommended factors were conservative

- $\quad$ The recommended factors of API for axially loaded piles were appropriate in clayey soils. For axially loaded piles placed in sandy soils and laterally loaded piles placed in sandy and clayey soils, the calculated factors were conservative

- As presented in Table 3 and 4, in SSL 2, the earthquake loading factor and the system ductility was less than SSL3. In SSL2, because of less importance of the structure, elements resistance factors were more than factors for SSL3, as presented in Table 2. Comparing the element resistance factors of two SSLs, it seems that API recommended factors were more appropriate for SSL3 and were conservative for SSL2.

As it can be seen in the Table 5 and 6, increasing of uncertainties in determining the earthquake-induced forces, will increase earthquake loading factor. 
Additionally, with increasing uncertainties, the probabilities of failure will increase. As a result, the earthquake loading factor and reserve strength ratio's increasing is instinct.

The pushover curves of piles were also shown in Fig. 6-9. As it can be seen BNWF model could predict nonlinear behavior of piles.

The drops in pushover curves have happened because of buckling of platforms braces. Therefore nonlinear fiber elements could predict buckling load and post buckling behavior of platforms as it mentioned in Ref. number ${ }^{[2]}$.

\section{CONCLUSION}

In this research, parameters of probability-based method and earthquake LRFD design method were evaluated for the two platforms which were located in Persian Gulf. To evaluate these parameters, the platforms were modeled accurately. The pile-soilstructure interaction was considered by using nonlinear $\mathrm{p}-\mathrm{y}, \mathrm{t}-\mathrm{z}$ and $\mathrm{q}-\mathrm{z}$ curve. Moreover, the buckling and postbuckling behavior of the braces was considered. Consequently, the results had good accuracy and were reliable.

Effect of change in SSL and amount of uncertainties on determining earthquake induced forces were investigated.

The geometry of jacket and different types of braces is important in the capacity and the behavior of offshore platforms. In the rows that $\mathrm{X}$ braces were used, the mean residual strength ratio and mean ductility were in the recommended range, but in the rows that chevron braces were used or in the absence of braces in the top story of platform (because of float over installation), the mean residual strength ratio and mean ductility were out of the recommended range. Therefore, using $\mathrm{X}$ braces is recommended.

Although API recommended element resistance factors were more appropriate for SSL 3, there were some differences between the results of reliabilitybased method evaluated factors and API recommended factors. In some cases, reliability-based method evaluated factors conservative.

\section{REFERENCES}

1. Bea, R.G., 1999. Reliability based earthquake design guidelines for marine structures. J. Waterway, Port, Coastal Ocean Eng., 125: 219-231.
2. Asgarian, B., A.A. Aghakouchak and R.G. Bea, 2006. Nonlinear analysis of jacket-type offshore platforms using fiber elements. J. Offshore Mech. Arctic Eng., 128: 224-232.

3. Boulanger, R.W., J.C. Curras, B.L. Kutter, D.W. Wilson and A. Abghari, 1999. Seismic soilpile-structure interaction experiments and analysis. J. Geotechnical Geoenvironm. Eng., 125: 750-759.

4. El-Naggar, M.H. and K.J. Bentley, 2000. Dynamic analysis for laterally loaded piles and dynamic p-y curves. Can. Geotechnical J., 37: 1166-1183.

5. American Petroleum Institute, 1993. Recommended Practice for Planning, Designing and Constructing Fixed Offshore Platforms, API Recommended Practice 2A-LRFD (RP 2A-LRFD), 20th Edition, Washington, D.C., pp: 115-121.

6. Silvia Mazzoni, Frank McKenna and Gregory L. Fenves et al., 2006. Opensees 1.6.0 User's Manual pp: 204-208.

7. Chopra, A.K. and R.K. Goel, 2001. A modal pushover analysis procedure to estimate seismic demands for buildings: Theory and preliminary evaluation. Rep. PEER., 2001(03): 65-68.

8. Bea, R.G., 1992. Seismic design and requalification methodologies for offshore platforms. Proc., Int. Workshop on Seismic Des. and Requalification of Offshore Struct., pp: 44-67.

9. Bea, R.G., 1993. Reliability based requalification criteria for offshore platforms. Proc. OMAE'93, pp: 133-147.

10. Miranda, E. and V.V. Bertero, 1994. Evaluation of strength reduction factors for earthquake-resistant design. J. Earthquake Spectra, 10: 110-140.

11. Hellan, O., T. Tandberg and N.C. Hellevigt, 1992. Nonlinear reassessment of jacket structures under extreme storm cyclic loading. Proc. OMAE'93, pp: 55-66.

12. Bazzurro, P. and C.A. Cornell, 1994a. Seismic hazard analysis of nonlinear structures. I: Methodol. J. Struct. Engrg., ASCE., 120: 33203344.

13. Bazzurro, P. and C.A. Cornell, 1994b. Seismic hazard analysis of nonlinear structures. II: Appl. J. Struct. Engrg., ASCE., 120: 3345-3365. 